\title{
AMAZÔNIA E A CARREIRA DAS ÍNDIAS: navegação para o norte da América portuguesa na época da Monarquia Hispânica ${ }^{1}$
}

por

Alírio Cardoso

Universidad Federal de Maranhão (Brasil)

O antigo Estado do Maranhão e Grão-Pará, hoje equivalente aos atuais estados da Amazônia brasileira, não pertencia às rotas de navegação para o Estado do Brasil. Durante a primeira metade do século XVII, os portugueses que habitavam essa região planejaram participar da Carreira das Índias aproveitando a facilidade de navegação até o Vice-Reinado do Peru e para o Caribe. Este artigo tem como objetivo analisar a reação dos portugueses das zonas de fronteira com relação à integração de Portugal à Monarquia Hispânica (15801640). Para este trabalho foram utilizadas fontes sobre as diversas propostas de participação portuguesa na rota de navegação hispano-peruana, disponiveis hoje em diferentes arquivos portugueses, brasileiros e espanhóis.

Palavras Chave: Amazônia; Estado do Maranhão; Monarquia Hispânica; navegação; séculos XVII.

ROTAS POSSÍVEIS

O Estado do Maranhão e Grão-Pará, ou simplesmente Estado do Maranhão, era um enorme território que hoje em dia corresponderia aos atuais estados

\footnotetext{
${ }^{1}$ Este artigo é uma parte, modificada, de minha tese de doutorado inédita: "Maranhão na Monarquia Hispânica. Intercâmbios, guerra e navegação nas fronteiras das Índias de Castela (1580-1655)", defendida na Universidad de Salamanca (2012). O autor agradece aos professores Dr. José Manuel Santos Pérez, da Universidad de Salamanca, Dr. Pedro Cardim, da Universidade Nova de Lisboa, e Dr. Rafael Chambouleyron, da Universidade Federal do Pará (Brasil), pelos conselhos e sugestões referentes a este texto.
} 
da Amazônia Brasileira (principalmente Amazonas, Amapá, Pará e Tocantins), mais Maranhão, Ceará e Piauí. Esta região foi conquistada em 1615 em uma ação militar internacional que também contou com financiamento da Coroa espanhola. ${ }^{2}$ A partir de 1621, a América portuguesa encontra-se então dividida em duas grandes unidades administrativas, o Estado do Maranhão, ao norte, cuja capital era a cidade de São Luís, e o Estado do Brasil, ao sul, cuja capital era a cidade de Salvador. Estas duas unidades políticas eram independentes entre si. O Estado do Maranhão também estava dividido em duas capitanias reais, Capitania do Maranhão e Capitania do Grão-Pará, conquistadas por ordem direta de Filipe III. Existiam outras capitanias particulares, criadas por mercê real e cujas mais importantes eram: Tapuitapera, Cametá, Caeté, Ilha de Joanes e o Cabo do Norte (este último, mais ou menos equivalente ao atual Estado do Amapá).

Este artigo tem dois objetivos. Em primeiro lugar, pretendemos definir os limites da navegação entre o Estado do Brasil e o Estado do Maranhão, correspondentes aos problemas da navegação entre o Atlântico Sul (Brasil) e a faixa equinocial do Atlântico Norte (Maranhão); em segundo lugar, pretendemos demonstrar como os primeiros moradores portugueses do Estado do Maranhão tentaram convencer a Coroa espanhola sobre as vantagens da inclusão destas novas terras nos circuitos da Carreira das Índias. Em todo caso, para os luso-maranhenses o argumento mais convincente a favor da inclusão do Maranhão no comércio castelhano era a sua condição de fronteira, localizado apropriadamente entre o Brasil, o Vice-Reinado do Peru e o Caribe. Assim, estes portugueses tentaram inventar uma vocação comercial para as novas terras da Monarquia a partir da própria situação geopolítica criada com a união monárquica entre Portugal e Espanha (1580-1640).

No início do século XVII, o conhecimento acerca das vicissitudes da navegação oceânica já é razoavelmente confiável. ${ }^{3}$ Desta forma, em tese, as novas regiões da Monarquia Hispânica não teriam problemas em rapidamente identificar uma vocação comercial, ajustando-se às rotas pré-existentes ${ }^{4}$. Por outro lado, muitos conselheiros do Monarca Católico não tinham dúvidas de que a integração econômica de territórios de fronteira era a única forma re-

2 Cardoso, 2012.

${ }^{3}$ Ver entre outros: Mauro, 1995: 69-76.

${ }^{4}$ Segundo a síntese feita por Russell-Wood, é possível definir três rotas inter-regionais para América Portuguesa durante o século XVII: 1. O comércio local de provisões, que combinaria rotas marítimas e fluviais pela costa do Estado do Brasil; 2. O comércio costeiro, que transportava os gêneros que chegavam da Europa e África; 3. A troca de produtos específicos entre as capitanias. Russel-wood, 1992: 65. 
almente eficaz de protegê-los do assédio dos concorrentes europeus. Esta foi claramente a expectativa sobre a mais nova conquista de Filipe III: o Maranhão.

Tal como afirma Russell-Wood, as condições naturais para a circulação marítima influenciaram significativamente os padrões e a cronologia das próprias conquistas ultramarinas. ${ }^{5}$ Com efeito, era perfeitamente possível para um navegador experiente comparar os limites impostos pelos anticiclones do Atlântico, que separavam a América portuguesa em duas zonas de ocupação, quase isoladas, ao sistema de monção presente, por exemplo, na navegação pelo oceano Índico. ${ }^{6}$ De fato, os portugueses estavam bem acostumados com estas circunstâncias do mar. No caso do Maranhão, qualquer navegador sabia que viajar de Lisboa para a cidade São Luís era bem mais fácil que viajar de São Luís para Salvador, em função dos ventos alísios de Nordeste. Os limites impostos ao acesso à rota do Estado do Brasil acabam por alimentar outras opções. Mas, antes de qualquer coisa, é necessário identificar exatamente que limites eram estes.

O Estado do Maranhão não pertence ao sistema de ventos e correntes oceânicas que define os espaços possíveis da carreira do Brasil. Com efeito, esta nova conquista não poderá ser considerada nos limites deste trabalho como parte natural da rota de navegação para o Atlântico Sul. Ao contrário, o Maranhão inclina-se naturalmente ao sistema alimentado pela corrente Norte Equatorial, e pela contracorrente Equatorial, bem mais próximas dos condicionamentos do Atlântico Norte. Dito de outro modo: o Maranhão não é parte do Atlântico Sul, ao menos do ponto de vista da sua localização geográfica e das possibilidades de circulação comercial ensejadas por ela.

Outras duas correntes oceânicas têm influência sobre a região: a corrente dos Açores, que corre de Leste para Oeste, e a corrente das Guianas, que corre em direção Noroeste e potencializa a conexão entre o Norte da América portuguesa e o mar do Caribe. Tais limites não eram, de modo algum, desconhecidos. Ao contrário, há inúmeros testemunhos de época que afirmam existir uma separação física entre o Estado do Brasil e o «Maranhão». Para resumir de uma forma bem direta, o padre jesuíta Luís Figueira, em 1609, definiu bem a situação: «os que lá forem não podem ter comércio com esta província do Brasil, porque de Pernambuco para lá [Maranhão] todos os ventos são em popa, e de lá não se navega para cá». ${ }^{7}$ No mesmo tom, o capitão Alexandre de Moura, no primeiro informe oficial sobre a nova conquista, explica a Filipe

\footnotetext{
${ }^{5}$ Russell-Wood, 2010: 177.

${ }^{6}$ Reid, 1988. Para uma crítica a esta análise ver: Subrahmanyam, 1994.

7 "Carta de Luis Figueira sobre as dificuldades da missão do Maranhão. 26 de Agosto de 1609”, Barão de Studart, 1904: 43-45. Atualizamos a grafia.
} 
III que o Maranhão está «longe do Brasil», e que «mais facilmente se vai a Portugal do que vai a ele». ${ }^{8}$ Neste caso, a principal barreira é a corrente do Atlântico Sul, que corre em sentido contrário aos ponteiros do relógio, como é bem conhecido, e que favorece a conexão rápida entre o Estado do Brasil e Angola, mas deixa poucas alternativas à conexão com o Maranhão. ${ }^{9}$ Nesse sentido, tal como alertavam os informes oficiais, sempre foi bem mais fácil ir do Maranhão ao reino de Portugal.

Uma viagem entre Lisboa e São Luís durava cerca de 5 semanas, um percurso bastante rápido e seguro para os padrões da época. Em comparação, um navio que viajasse de Lisboa para o Recife tardava cerca de 65 dias; de Lisboa a Salvador uma embarcação poderia levar 70 dias. Tudo dependia da monção favorável, com chegada limite até o mês de Junho, pois a partir deste limite a viagem tornar-se-ia mais arriscada. ${ }^{10} \mathrm{Na}$ costa do Estado do Brasil, entre Pernambuco e Bahia, os deslocamentos oceânicos são facilitados pelos ventos de Sudeste que sopram com regularidade entre Abril e Outubro. ${ }^{11}$ Estes ventos tornam a comunicação regular com o Maranhão virtualmente impraticável. Entre o Maranhão e o reino de Portugal os melhores meses para a travessia são Abril, Maio e Junho. Nesta rota as ilhas atlânticas funcionam como escala natural, sobretudo os Açores. ${ }^{12}$ As ilhas também serviam de rota de migração. Com efeito, as cidades do Estado do Maranhão receberiam contingentes de população açoriana principalmente entre os anos de 1619 e 1677. ${ }^{13}$ Tal como sustentam os estudos de Rodrigues e Chambouleyron, entre outros, este movimento migratório entre as ilhas atlânticas e o Maranhão é incentivado pela Monarquia, motivado por diferentes fatores, e sobrevive até a primeira metade do século XVIII. ${ }^{14}$

Se a ligação entre o Brasil e o Maranhão é dificultosa pelo mar, por terra os desafios são ainda piores. Até o final do século XVIII, não há estradas ou caminhos de mata ligando efetivamente o Estado do Brasil à

${ }^{8}$ OFÍCIO do capitão-mor do Maranhão, Alexandre de Moura, ao rei Filipe II, sobre a tomada da fortaleza francesa de São Luís. Faz referências ao estado geral do Maranhão; ao estabelecimento de índios em Tapuitapera; ao reconhecimento de alguns rios e ilhas; $\grave{a}$ qualidade das terras e à importância do povoamento desta região, Lisboa, 24 de Setembro de 1616, Arquivo Histórico Ultramarino (AHU), Maranhão (avulsos), cx. 1, doc. 8.

9 Sobre a conexão entre o Estado do Brasil e Angola, ver: Alencastro, 2000.

${ }_{10}$ Russel-wood, 1992: 52-55. Lapa, 1968: 140.

11 Mauro, 1997: 112.

12 É preciso dizer que, pela posição geográfica das ilhas dos Açores, o tráfico entre estas e o Estado do Brasil também foi constante desde o início do século XVII. Rodrigues, 2003: 150-1.

${ }^{13}$ Coates, 1998: 145-46.

${ }^{14}$ Chambouleyron, 2008: 187-204. Rodrigues, 2003: 247-263. 
Amazônia Portuguesa. ${ }^{15} \mathrm{~A}$ única ligação possível seria através da perigosa serra de Ibiapaba, entre o Ceará e o Piauí. Ibiapaba, por sua vez, estava longe de ser uma opção segura. Em 1608, o padre Francisco Pinto tornarse-ia o primeiro «mártir» da Companhia de Jesus no Maranhão ao morrer nas mãos dos índios «cararijus», quando tentou atravessar esta perigosa serra. ${ }^{16}$ No entanto, nos conturbados anos da guerra aos holandeses no Brasil (1625-1654), o Ceará poderia servir de escala na comunicação forçosa entre o Estado do Brasil e o Estado do Maranhão. No regimento passado ao capitão Domingos Lopes Lobo, ainda em 1617, D. Luís de Sousa deixa patente esta condição especial. Sousa, então governador do Estado do Brasil, adverte de que uma das obrigações do capitão do Ceará é receber bem os viajantes desta rota, tornando a passagem ao Maranhão cômoda e segura. ${ }^{17}$ Em 1619, outro capitão-mor, o já famoso Martim Soares Moreno, na carta que enviou a Filipe III solicitando reformas para a proteção da capitania, descreve o Ceará como «necessária escala dos navios e caminhantes que vão do Brasil ao Maranhão». ${ }^{18}$

Contudo, o mesmo Martim Soares, já experimentado nesta rota, nunca concordou com a decisão de Filipe IV de sujeitar a Capitania do Ceará à jurisdição do Estado do Maranhão. Em 1626, o capitão deixa claro o seu desacordo, por julgar ser esta rota «inavegável por respeito das águas e ventos correrem sempre em contrário». ${ }^{19}$ Evidentemente, não se pode reduzir a complexidade da situação política da Capitania do Ceará a uma questão de ventos e correntes oceânicas. Martim Soares Moreno tentava, ao mesmo tempo, construir uma posição política independente com relação ao Estado do Brasil, consciente dos privilégios que poderia obter governando, desta forma, uma capitania de fronteira, aliás, rica em salinas e com capacidade de transferência de contingentes indígenas para a guerra contra os holandeses no Brasil. ${ }^{20}$ De qualquer forma, uma estadia no Ceará era fundamental para quem

15 Russel-Wood, 1992: 79.

${ }^{16}$ Cardoso y Chambouleyron, 2003: 33-62.

17 "Copia do regimento que leva o cappitam do Siara", Olinda, 9 de Setembro de 1617, Livro 2. ${ }^{\circ}$ do Governo do Brasil (1615-1634), Lisboa, CNCDP/Museu Paulista/USP, 2001: 66-67.

18 REQUERIMENTO do Capitão-mor do Ceará, Martim Soares Moreno, ao rei [D. Filipe II], a pedir meios para reconstruir a fortaleza, soldados e seus oficiais, armas, munições e pólvora para defesa dos ataques dos holandeses e franceses, e escala dos navios que do Estado do Brasil vão ao do Maranhão, Ceará, 25 de Maio de 1619, AHU, Ceará (avulsos) cx. 1, doc. 3.

${ }_{19}$ REQUERIMENTO do Capitão-mor do Ceará, Martim Soares Moreno, ao rei [D. Filipe II], a pedir que a capitania do Ceará, por facilidade de comunicação, pertença ao estado do Brasil e não ao do Maranhão, Ceará, 11 de Fevereiro de 1626, AHU, Ceará (avulsos), cx. 1 , doc. 7 .

${ }^{20}$ Cardoso, 2012. 
pretendesse viajar com alguma segurança entre o Brasil e o Maranhão. Um dos recordes desta rota pertence ao navio que transportava o frei Cristovão de Lisboa, novo custódio dos franciscanos do Estado do Maranhão. O navio do Frei Lisboa saiu do Recife em 12 de Julho, fazendo escala no Ceará no dia 17, deixando aquela fortaleza no dia 30, e chegando a São Luís no dia 5 de Agosto de 1624. ${ }^{21}$

Tal como veremos, a participação do Maranhão nas rotas sul-atlânticas nunca foi completamente descartada. Entretanto, as conexões sonhadas por alguns dos seus primeiros moradores tinham como alvo o Caribe e o Vice-Reinado do Peru. Seriam, em tese, carreiras interfluviais, com uma parte da jornada feita também por mar. Estas rotas foram pensadas para tirar vantagem de uma conhecida peculiaridade da Amazônia Portuguesa, seu complexo sistema de rios. Diferentemente do Estado do Brasil, os rios do Maranhão apresentam um nível de navegabilidade inigualável, semelhante a certos sistemas fluviais asiáticos. ${ }^{22}$ No final da década de 1630 , surge um imenso debate sobre as rotas fluviais amazônicas, por ocasião da espantosa viagem de Pedro Teixeira entre Belém e Quito (1637-1639). Em 1639, são produzidos diversos informes «peruanos» sobre o tema. D. Martin de Saavedra Guzmán, governador do Novo Reino de Granada, nas cartas e relações que escreveu a respeito, especulou acerca dos limites do rio Amazonas, comparando-o com outros grandes rios do mundo: o Ganges, o Nilo, o Eufrates, e os rios do golfo de Bengala. Ao final, Saavedra Guzmán admite que aquele rio parece não ter limites, podendo sua extensão chegar à serra de Potosí e às ilhas do Caribe. Na sua Relación del descubrimiento del Rio de las Amazonas (1639), Saavedra Guzmán afirma que: «por todas partes corre este famoso Rio, manso, y ledo, de suerte que todo es navegable sin corriente que impida a las embarcaciones». ${ }^{23}$ Foi exatamente esta condição especial da rede fluvial amazônica que inspirou diversas ideias e especulações acerca da vocação econômica da região.

O próprio mito cartográfico que sustenta a existência de uma «Ilha Brasil», popular entre os cosmógrafos do período, parece ser uma expressão extrema do potencial destes corredores fluviais, e de como estavam presentes no imaginário dos contemporâneos. Se, de um lado, este mito reforça a noção de que o Estado do Brasil estava fisicamente separado do Maranhão, por outro lado, reafirma a aproximação entre o Maranhão e as zonas que participavam das

${ }^{21}$ Berredo, 1988: 138-9. Kiemen, 1954: 32.

${ }^{22}$ Holanda, 2000: 207.

${ }^{23}$ Relacion del descubrimiento del Rio de las Ama=zonas, y San Francisco del Quito, $y$ declaracion del Mapa donde esta pintado, Santa Fé, julho de 1639, Biblioteca da Ajuda (Lisboa), códice 54-XI-26 ( $\left.\mathrm{n}^{\circ} 4\right)$, fl. 19. 
rotas castelhanas, como o rio da Prata. ${ }^{24}$ Entretanto, navegar por estas águas implicava outras dificuldades, como veremos a seguir.

\section{NAUS, CARAVELAS E CANOAS}

Tais rotas só seriam possíveis se existissem transportes apropriados. Com efeito, desde o início da conquista as autoridades locais sabem que, além de moradores e soldados, o Estado do Maranhão necessitava urgentemente de navios. Nada mais lógico para um território dominado constantemente pelas águas. Entretanto, durante todo o século XVII, e até inícios do século XVIII, o Maranhão recebe um número insuficiente de embarcações por ano. Em parte, esta é uma consequência de estar fora dos circuitos regulares da carreira do Brasil. No fim do século XVII, mesmo a comunicação com Lisboa torna-se irregular, como fica claro nas diversas queixas dos moradores luso-maranhenses. ${ }^{25}$ Entretanto, existiu um fluxo maior de embarcações nos primeiros anos de conquista, consequência das demandas necessárias à formação da nova unidade política, e das contingências da guerra hispano-holandesa. Neste período, o Maranhão é visitado por caravelas do reino de Portugal, responsáveis pela transferência do corpo burocrático; naus francesas e inglesas, traficando entre os braços do rio Amazonas; ou, ainda, com a movimentação defensiva das décadas de 1630-1650, anos quentes da Guerra do Brasil. Seja como for, nestes anos as águas maranhenses estavam mais agitadas.

Não há muitas informações sistemáticas sobre o tipo de transporte e a tonelagem média das embarcações que frequentavam os portos das cidades de São Luís e Belém até 1655. Em função da ecologia local, o uso de naus de grande calado não era incentivado. Apesar de, no século XVII, existir uma tendência geral para o aumento do tamanho médio das embarcações, ${ }^{26}$ sabe-se que as circunstâncias da guerra hispano-holandesa impulsionaram o ressurgimento da caravela, pequena e ágil, em muitos sentidos mais útil que as grandes naus. ${ }^{27} \mathrm{~A}$ navegação amazônica é, por excelência, uma transição entre o mar e o rio, conveniente às caravelas de pequeno e médio porte (até

${ }^{24}$ Kantor, 2007: 70-80.

25 Chambouleyron, 2005: 209-215.

${ }^{26}$ Mauro, 1997: 79-80. No século XVII, esta tendência verifica-se também nos navios de guerra. Unger, 1997: 25.

${ }^{27}$ Costa, 2002: 606-7. Para o período anterior: Costa, 1997. Para uma síntese, ver: Ballabarba, 1993: 99-123. 
300 toneladas) parecidas com as utilizadas pelos portugueses na navegação pela costa africana. ${ }^{28}$

É necessário, também, diferenciar as embarcações da travessia oceânica, daquelas que faziam as rotas internas entre as capitanias. Na Capitania do Maranhão, como de resto costumava ocorrer, era a Câmara de São Luís que regulamentava as embarcações que faziam o transporte de pessoas ou mercadorias, sobretudo na pequena "carreira», como era chamada a travessia entre a ilha de São Luís e a «terra firme» de Tapuitapera (atual Alcântara). ${ }^{29} \mathrm{Em}$ 1656, por exemplo, a Câmara manda passar aviso aos mestres de barcos para que não partissem sem antes prestar contas aos oficiais sobre a renda proveniente destas travessias. ${ }^{30}$ A Câmara também regulava os barcos que faziam a jornada para a Capitania do Pará, onde muitos luso-maranhenses tinham seus negócios e para onde se deslocavam com certa regularidade.

Os portugueses rapidamente aprenderam nos encontros com traficantes e piratas que a tecnologia das embarcações nativas não deveria ser ignorada. O sistema de navegação utilizado na região amazônica, assim, inclinava-se a uma mescla de conhecimentos europeus e indígenas. É verdade que o uso de embarcações nativas não era novidade entre os portugueses, habituados aos barcos de junco das Molucas ou aqueles da passagem dos estreitos de Macau. ${ }^{31}$ No caso do Maranhão, a dependência das embarcações indígenas vai ser agravada pela falta generalizada de carpinteiros nos primeiros anos, queixa reiterada em diversos documentos. ${ }^{32}$

Barcos pequenos eram fundamentais, e os portugueses rapidamente dão conta disso. Ainda em 1612, num parecer sobre o combate aos franceses que então ocupavam a região, D. Diogo de Menezes afirma que a navegação pelo interior da costa do Maranhão é «impossível a navios grandes redondos, e dificultosa aos latinos grandes, e fácil a embarcações pequenas de remos»». ${ }^{33}$ Em 1615, na chegada de uma frota de socorro comandada pelo português Alexandre de Moura, os navios maiores foram guiados por um batel e uma

${ }_{28}$ Russel-Wood, 1992: 47. Ver também: Carreira, 1984.

${ }^{29}$ Corrêa, 2011: 130.

30 "Barcos", [à margem], São Luís, 20 de fevereiro de 1656, Livro de Acórdãos, Arquivo Público do Estado do Maranhão (APEM), fl. 41ª .

31 Russel-Wood, 1992: 48.

32 CARTA do capitão-mor do Maranhão, Diogo da Costa Machado, ao rei Filipe II, sobre as necessidades do Maranhão: fabrico de engenhos, construção de Navios, mineiros, alimentos para os visitantes, animais, armas e munições, 10 de Dezembro de 1619, AHU, Maranhão (avulsos), cx. 1, doc. 35.

33 "Carta de Diogo de Menezes, feita em a Bahia a 1 de Março de 1612", Anais da Biblioteca Nacional do Rio de Janeiro (ABNRJ), 26 (1904): 310. 
lancha, por não haver, segundo explica o piloto-mor Manuel Gonçalves, «piloto que se atrevesse a meter tamanhas naus por dentro». ${ }^{34}$ Não só os portugueses conheciam as circunstâncias da navegação amazônica. Os primeiros franceses que se estabeleceram na região (1612-1615) sabiam perfeitamente que as naus maiores eram de pouca utilidade, e deveriam ser substituídas pela lancha, o lanchão, ou o batel. Em 1615, esta foi justamente a advertência que fez o general francês Daniel de La Touche a Alexandre de Moura, quando perguntado sobre as condições de navegabilidade entre a cidade de São Luís e o rio Amazonas. Segundo uma certidão do general francês, traduzida para o espanhol: «del Marañón hasta dichas barras y puertos no tenemos pilotos que sepan llevar naos grandes por de fuera de los bajos, y por de dentro no navegan, sino navíos pequeños». ${ }^{35}$ Entre os «navíos pequeños» utilizados pelos portugueses, mas também por franceses, ingleses e holandeses, estava a canoa indígena.

A história da expansão portuguesa pelo interior da Amazônia não poderia ser devidamente contada sem referência à canoa. ${ }^{36}$ Este tipo de transporte nativo era fundamental como embarcação guia entre os canais estreitos, e na identificação das zonas de baixios. Tal a funcionalidade deste engenho que substituirá, com vantagens, o universo de embarcações auxiliares, o barco, o batel, o esquife, a sumaca, e a falua de 10 metros, que os portugueses utilizavam na transição entre o mar e os sistemas fluviais. ${ }^{37} \mathrm{Na}$ "Declaração do que contem o Mapa dos portos do Rio das Amazonas até a Ilha de Santa Margarida, donde se pescão as perolas", manuscrito do início do século XVII, consta que os rios da região "se han de subir llevando a cuestas arriba unas barcas llamadas canoas con que se navega de una subida a otra». ${ }^{38}$ Acostumado com elas, o padre jesuíta Luís Figueira, em 1636, explica que as canoas amazônicas são «hũas embarcações pequenas feitos de hum só pão cavado e aberto com fogo, como um batel, compridos porem de 50. 60 e 70 palmos mui ligeras». ${ }^{39}$ A canoa amazônica poderia ser conhecida pelos

\footnotetext{
34 "Roteiro de Pernambuco ao Maranhão" 5 de Outubro de 1615, Livro $1^{\circ}$ do Governo do Brasil (1607-1633), Lisboa, CNCDP/MRE, 2001: 154. Atualizamos a grafia.

35 “Certidão do Francês", São Luís, 8 de Dezembro de 1615, ABNRJ, 26 (1904): 237.

${ }^{36}$ Ver, por exemplo: Delson, 1995: 1-28.

37 Domingues, 2004: 241-286.

38 Declaração do que contem o Mapa dos portos do Rio das Amazonas atè à Ilha de Santa Margarida, donde sell pescão as perolas, [início do século XVII], Biblioteca Nacional de España, mss 3015, fl o $^{\circ} 139$.

${ }^{39}$ Figueira, Luis, S. J., "Missão que fez o Pe. Luis Figueira da Companhia de Jesus, superior da residência do Maranhão, indo ao Grão-Pará, Cametá e Gurupá, capitanias do rio das Almazonas no ano de 1636”, Serafim Leite, 1940: 182.
} 
nomes indígenas ubá ou igara, e era sempre feita de casca de árvore cavada. Utilizava-se como ferramenta o fogo, depois substituído pelo machado, sem o emprego de cravos ou pregos. À diferença de alguns modelos encontrados no Estado do Brasil, a canoa amazônica é sempre movida a remo, não utilizando velas ou mastros. ${ }^{40}$

A canoa também poderia atingir tamanhos maiores de acordo com o percurso e as condições oferecidas por cada curso de rio específico. Em todo caso, era bem mais eficiente no transporte rápido de mercadorias e homens pelos canais estreitos. Segundo Sérgio Buarque de Holanda, as igaras amazônicas feitas de jatobá eram leves e resistentes, podendo carregar $500 \mathrm{~kg}$ de peso, e navegar mais de $130 \mathrm{~km}$ ao dia. ${ }^{41}$ Este tipo de transporte tradicional será um recurso importante para o comércio da região até o século XIX, rivalizando com os primeiros barcos a vapor. ${ }^{42}$ No século XVII, torna-se cada vez mais comum a utilização de canoas de guerra, adaptadas para uma abordagem rápida e furtiva. De fato, no Vocabulário Português Latino de Raphael Bluteau, canoa é definido como «embarcação de que usam os gentios da América para a guerra». ${ }^{43} \mathrm{Tal}$ a importância atribuída à «canoa» como embarcação de primeiro ataque, que não seria exagerado dizer que a guerra hispano-holandesa na Amazônia inventou uma espécie de infantaria fluvial. ${ }^{44}$

É possível encontrar bons exemplos desta estratégia nos relatos sobre o assédio português aos Fortes holandeses instalados no Estado do Maranhão. ${ }^{45}$ Em 1624, por exemplo, durante o ataque ao Forte Nassau, nas margens do rio Xingu, os portugueses colocaram à prova a utilidade destas pequenas embarcações, combatendo navios holandeses de mais de 100 toneladas. Na ocasião, os vassalos de Filipe IV deixaram no porto da Capitania do Pará uma caravela de 60 toneladas, e seguiram viagem em um pequeno barco, uma lancha e mais 40 canoas de guerra, segundo afirma o capitão português Antônio Vicente Cochado. ${ }^{46}$ Por outro lado, é difícil saber com certeza quais tipos de embarcações foram utilizadas na campanha de 1624. Os navios holandeses, por exemplo, são genericamente chamados pelos portugueses de «naus». Sabe-se que, a partir do século XVII, o barco de guerra regular dos holandeses era a

${ }^{40}$ Camara, 1888: 31-74.

${ }^{41}$ Holanda, 2000: 208-9.

42 Tavares Bastos, 1866: 279. Ver também: Bastos y Lopes, 2008: 159-188.

${ }_{43}$ Bluteau, 1712.

${ }^{44}$ Cardoso, 2012. Ver capítulo VI.

45 Santos Pérez, 2009.

46 Relação que faz Antonio Vicente Cochado do descobrimento do rio das Almazonas, e Cabo do Norte, que foi fazer por orden de V.Mag de 27 de Julio de 1624, Archivo General de Simancas (AGS), Secretarias Provinciales (SP), 1467, $\mathrm{fl}^{\circ}$ 688-688v. 
fragata. ${ }^{47}$ Entretanto, os navios holandeses encontrados na campanha de 1624 pareciam ser embarcações de transporte de mercadorias. Tratar-se-ia, talvez, dos cargueiros conhecidos como fleuten. ${ }^{48}$

Embora as embarcações pequenas fossem mais eficientes e versáteis no acesso às zonas fluviais, e na vigilância de áreas críticas, os portos mais importantes do Estado do Maranhão (São Luís e Belém) eram identificados como ideais para circulação de navios de grande calado. O próprio Claude D'Abbeville, cronista da ocupação francesa do Maranhão (1612-1615), afirma que o porto da cidade de São Luís poderia abrigar navios de 1200 toneladas. ${ }^{49}$ Acreditava-se que os próprios índios construtores de canoas poderiam ser utilizados na fabricação de grandes navios. No manuscrito anônimo Descripción de la Província del Brasil (1629), seu autor estima que nos portos de Pará, Maranhão e Ceará seria possível fabricar, cada ano, 12 galeões de 1000 toneladas cada que sairiam da região «cargados de madera labrada para hacer otros galeones en España, porque hay muchas y mui buenas y fáciles de traer adonde se hubiere de hacer la fabrica, y costará $4 U$ escudos de a diez $\mathrm{R}^{\mathrm{s}}$ cada una toneladas»». ${ }^{50}$ No mesmo sentido, João de Almeida, construtor de navios do reino de Portugal, com mais de 30 anos de experiência neste ofício, explica que pelas informações que tinha no Maranhão «a pouco custo se podem fazer grande quantidade de embarcações». Segundo Almeida, não seria necessário enviar de Portugal os trabalhadores, pois os índios da região poderiam ser carpinteiros, ferreiros, ou torneiros. ${ }^{51}$

Além da possibilidade de utilização do trabalho indígena, o Maranhão teria outra vantagem: a enorme quantidade de madeiras adequadas à construção naval. Tal como afirma Mauro, o século XVII foi um período de aumento considerável do número de estaleiros na América portuguesa. A Monarquia esperava com isso aproveitar a excelência das madeiras do Brasil e do Maranhão e, ao mesmo tempo, diminuir a importação deste produto dos países do Norte da Europa..$^{52} \mathrm{Na}$ época, os estaleiros portugueses tinham excedido sua capacidade, e a Ribeira das Naus encontrava-se em situação lastimável. Em 1616, por exemplo, o Conselho de Portugal foi obrigado a pedir emprestado galeões de Castela para suprir as necessidades

47 Parker, 2002: 139.

48 Wätjen, 2004: 526-27.

49 D’abbeville, 1975: 58.

50 Discripcion de la Provincia del Brasil, Madrid, 30 de setembro de 1629, Biblioteca Nacional de España (BNE), mss 3015, fl ${ }^{\circ}$ 2v.

51 CONSULTA do Conselho Ultramarino para o rei D. João IV, sobre uma memória acerca da fabricação de navios no Pará, Lisboa, 1 de Junho de 1644, AHU, Pará (avulsos), cx. 1, doc. 51 .

52 Mauro, 1997: 73-83. 
da frota da Índia. ${ }^{53}$ Para piorar, desde inícios do século XVII, há notícias sobre a carência de madeiras para construção naval até mesmo em Pernambuco, pelo excessivo uso que os engenhos de açúcar faziam delas. ${ }^{54}$ Por isso, existia a esperança de que as novas conquistas da América portuguesa pudessem resolver, em parte, o problema. Assim, em 1622 já houve uma tentativa de transportar madeira do Estado do Maranhão para o reino de Portugal nos navios de torna-viagem. ${ }^{55}$ Nos anos posteriores, encontramos outras tantas proposições semelhantes.

Ao menos no reinado de Filipe IV, o alvo privilegiado dessas propostas sobre o aproveitamento das madeiras do Maranhão foi a carreira das Índias espanholas. Numa carta enviada ao soberano, em 1637, o então governador do Maranhão, Jácome Raimundo de Noronha, expõe suas ideias a respeito. Noronha considera que os rios do Grão-Pará são os melhores para a construção de uma nova fábrica de naus, por onde seria possível chegar a Sevilha em 40 dias. ${ }^{56}$

Tais ideias seriam retomadas inclusive após o fim da união dinástica (1640). Em 1647, surge outra proposição. O governador do Estado, Francisco Coelho de Carvalho, escreve uma carta ao rei D. João IV, apreciada pelo Conselho Ultramarino em fevereiro de 1648, sobre a possibilidade de construção de uma fábrica de galeões na cidade de São Luís. A tal fábrica poderia abastecer a frota da carreira da Índia oriental, pois, segundo afirma o governador: «naquela baía de São Luís, e no Pará, há barras tão fundas e tão limpas que poderiam entrar e sair delas toda a embarcação, galeões e outras por grandes que sejam». ${ }^{57}$ Assim, mesmo no período da Restauração Portuguesa estas propostas conservavam, ainda, uma grande semelhança com aquelas proposições do período filipino.

Todos os caminhos levam à Prata Do Peru

A criação de um "eixo Andes-Atlântico», para usar a expressão de Guy Martinière, apresentava-se como possível solução para alguns dos conhecidos

53 Salgado, 2009: 79-80.

${ }_{54}$ Hutter, 1985: 418-419.

${ }_{55}$ OFÍCIO de Roque da Silveira, sobre os navios que vão para o Maranhão e que na viagem de regresso transportariam madeira para a fábrica das naus, Lisboa, 16 de Abril de 1622, AHU, Maranhão (avulsos), cx. 1, doc. 38.

56 "Relação dada por Jacome Raymundo de Noronha sobre cousas tocantes ao governo do Maranhão", 10 e 23 de maio de 1637, Barão de Studart, 1910: 260.

${ }^{57}$ CONSULTA do Conselho Ultramarino ao rei D. João IV, sobre o estabelecimento da fábrica de galeão, no Estado do Maranhão. Anexo, 2 consultas, Lisboa, 17 de Fevereiro de 1648, AHU, Maranhão (Avulsos), cx. 3, doc. 241. 
problemas da carreira das Índias. ${ }^{58}$ De fato, os moradores luso-maranhenses sabiam que um dos grandes inconvenientes da carrera era a escala dos galeões espanhóis na saída das Bahamas, sobretudo em Havana, e buscavam apresentar alternativas viáveis ao problema, com um bom toque de imaginação, é bem verdade. ${ }^{59}$ Esta solução também foi apresentada como possível resposta ao assédio holandês e inglês em Cartagena de Índias e em Portobelo. A ideia, basicamente, seria participar da rota que passava por Cartagena e cuja volta se fazia por Cuba em direção aos Açores. Uma alegada vantagem da inclusão do Maranhão seria o seu clima mais estável, em comparação com o do Caribe. Tal como explica Carlo Cipolla, além da pirataria, um dos perigos mais frequentes no dia-a-dia da carrera eram estas «violentíssimas tempestades» que destruíam completamente a formação defensiva das frotas. ${ }^{60}$ Além disso, a própria invernação nos portos americanos era extremamente cara. ${ }^{61} \mathrm{Como}$ vemos, as propostas que resumimos a seguir pressupõem um bom conhecimento da realidade da própria carrera.

A ideia de incluir o Maranhão na carrera consta de diversos documentos. ${ }^{62}$ São cartas, consultas, pequenos memoriais e relações, que traçam expectativas gerais sobre a vocação oceânica desta região. Em 1615, o Conselho de Portugal já discute algumas dessas possibilidades nas consultas realizadas sobre o que foi chamado de «empresa del Marañón». Nestas consultas, o rio Amazonas volta a ser representado como uma ligação privilegiada entre as duas partes da união monárquica. Segundo afirma um dos pareceres aquele rio estaria localizado exatamente «no meio das conquistas que as coroas de Castela e Portugal têm na América». ${ }^{63}$

Tal como avisa o texto, era comum que embarcações que tentassem viajar do Maranhão ao Estado do Brasil, contracorrente, desviassem o curso, alcançando posteriormente as ilhas do Caribe. Esta condição não é desconhecida na época e muitos pilotos portugueses já tinham experimentado tais dificuldades por mais de uma vez. Em 1615, num pequeno memorial, o capitão português Manoel de Sousa de Eça explora algumas possibilidades de inclusão do Maranhão na rota peruana. Neste documento, traduzido para o castelhano pelo secretário Tomás Gracian Dantisco, o capitão Eça afirma ter informações sobre as atividades ilegais

58 Martinière, 1991b: 126.

59 Sobre o tema, ver: Cardozo, 2007: 60-63.

${ }^{60}$ Cipolla, 2002: 37. Ver também: Serrano Mangas, 1989.

${ }^{61}$ Mena Garcia, 2004: 473.

${ }^{62}$ Cardozo, 2011: 165-176.

${ }^{63}$ Consulta Del Consejo de Portugal al Rey de España Felipe $3^{\circ}$ sobre la empresa del Marañon y de lo acaecido alli con unos franceses que pretendían extablecerse en aquella tierra", Madrid, 6 de abril de 1615, Archivo General Indias (AGI), Patronato, 272, R. 3. 
de ingleses, franceses e holandeses, sugerindo uma solução ao problema. Esses estrangeiros, segundo diz, já estariam utilizando os canais fluviais para traficar grãos, madeiras, açúcar e tabaco. Por isso, na opinião de Eça, a integração do Maranhão à rota da prata seria uma forma eficaz de retirar a concorrência europeia do negócio espanhol. ${ }^{64}$ Eça, um dos mais conhecidos «conquistadores do Maranhão», junto a Vicente Cochado, Alexandre de Moura, Bento Maciel Parente, e Martim Soares Moreno, sempre fez questão de demonstrar às autoridades de Madri o seu amplo conhecimento sobre a região. ${ }^{65}$ Esse discurso de autoridade, presente em cartas e memoriais, foi uma valiosa moeda de troca utilizada por militares portugueses na busca de cargos e mercês do Monarca Católico. ${ }^{66}$

Algumas das mais sistemáticas propostas de aproximação entre o Maranhão e o comércio das Índias espanholas foram elaboradas por Simão Estácio da Silveira, português que foi procurador-geral da Câmara de São Luís, e um dos seus fundadores em 1619. ${ }^{67}$ Este capitão de origem açoriana era, sem dúvida, um homem de muitas ideias. Em 1628, já se oferecia para, utilizando instrumentos necessários, tirar artilharia e outras coisas perdidas do «fundo da água», ganhando 4 mil cruzados para iniciar o projeto. ${ }^{68} \mathrm{~A}$ primeira intervenção sua sobre a participação maranhense na carrera aparece em 1618 , numa pequena relação chamada Intentos da Jornada do Pará, que ensaia já alguns dos argumentos presentes na sua obra mais famosa: Relação Sumaria das Cousas do Maranhão (1624). ${ }^{69}$ Tal qual muitos memoriais do período, o Intentos da Jornada do Pará traça uma linha de continuidade entre eventos do passado e do presente, ao descrever a própria conquista do Maranhão como o resultado lógico dos sucessos da navegação luso-espanhola por Pérsia, Índia, Arábia, Canárias e Brasil. ${ }^{70}$ Para Simão Estácio, a história desta conquista, antes de ser portuguesa ou espanhola, bem mereceria o título de hispano-lusa. ${ }^{71}$

${ }^{64}$ Roteiro do Rio das Amazonas, dado pelo capitão M. ${ }^{e l}$ de Souza Dessa al S. ${ }^{\text {or Vizorrey. }}$ Madrid, 7 de julho de 1615, AGI, Patronato, 272, R5. Também disponível em: ABNRJ, 26 (1904): 278. Atualizamos a grafia.

${ }^{65}$ Do mesmo capitão, ver: Breve relación de la Jornada de la Conquista del Marañon, AGI, Patronato, 272, R4. Também disponível em: ABNRJ, 26 (1904): 281-287.

${ }^{66}$ Ver também: Ofrecim. ${ }^{\text {to }}$ que faz Bento Maciel Parente de descobrir a sua custa todo o rio das Amazonas/Escripta em Moncão a 13 de março de 1626, fl ${ }^{\circ}$. 24, AGS, SP, 1520.

${ }^{67}$ Em muitos documentos, o próprio Simão Estácio da Silveira afirma ter chegado à região em 1618. Rodrigues, 1979: 81-82.

68 Simão Stacio da Silv. ${ }^{r a}, 15$ de novembro de 1628, Arquivo Nacional da Torre do Tombo (ANTT), Mesa da Consciência e Ordens, livro 30, fl ${ }^{\circ} 105$.

${ }^{69}$ Silveira, 1976.

${ }^{70}$ Hansen, 2004.

${ }^{71}$ Intentos da jornada do Pará, Lisboa, 21 de setembro de 1618, BNE, mss 2349, $\mathrm{fl}^{\circ}$ $174-177 \mathrm{v}$. 
De modo geral, em Intentos da Jornada do Pará admite-se que o rio Amazonas faz fronteira com três distintas regiões: Peru, mar do Caribe e bacia do rio da Prata. Para Simão Estácio, no futuro o Maranhão deveria fazer parte da integração do comércio hispano-luso através do complexo Marañón-Amazonas-Prata. O Amazonas, além disso, serviria como uma imensa estrada fluvial por onde portugueses e castelhanos levariam drogas, madeira, alimentos e metais preciosos entre o Pacífico e o Atlântico. O Maranhão também é apresentado como solução natural para alguns problemas de logística da carreira das Índias, ao poder abastecer com segurança toda a frota espanhola utilizando produtos nativos. Tudo isso seria feito mediante a confirmação dos caminhos naturais que seriam convertidos em rotas econômicas. Sobre o tema, explica Simão Estácio que:

Nas primeiras embarcações espero vadear o rio descobri-lo a [oeste], e pela outra ribeira contra água: observar as ilhas, as praias, e o gentio descrevendo tudo, e debuxando-o como sei fazer e achados os passos [reduzido] o gentio a abrir por este rio uma grande porta às riquezas do Peru por onde desçam a Espanha sem os grandes trabalhos e imensas despesas com que se acarretam ao mar do Sul e de Lima por mar a Porto Bello, e dai por terra a Havana e mar do Norte donde vem nas frotas da Nova Espanha cujo comércio se começa já a introduzir desde o rio da Prata, cujo nascimento há descido alguns castelhanos aos nossos. ${ }^{72}$

Apesar desta alegada autoridade nas «cousas do Maranhão», as propostas de Intentos da Jornada do Pará ainda careciam de sistematicidade e expõem algumas incertezas sobre o projeto. Foi durante os primeiros anos do reinado de Filipe IV, quando também a guerra global contra os holandeses já se faz sentir plenamente no Brasil, que Estácio da Silveira desenvolve melhor estas ideias prévias. Em 1626, Simão Estácio propõe ao monarca reduzir a viagem entre o Peru e a Espanha, de dez meses para apenas quatro, utilizando como corredor expresso o rio Marañón-Amazonas. O núcleo central da proposta é bastante ambicioso: substituir a rota usual entre as Bahamas e Sevilha, considerada perigosa em função das constantes tormentas e frequente ação de piratas holandeses, pela nova rota Maranhão-Peru-Sevilla. Escrita um ano depois da Restauração da Bahia, a petição de Estácio da Silveira parece completamente integrada ao clima belicista dos tempos do duque de Olivares, tentando sempre obter vantagens com a nova situação. ${ }^{73}$ A petição de Estácio da Silveira também desenvolve com eficácia um argumento crucial na época: não ligar o Maranhão às rotas da prata peruana seria dar uma oportunidade

\footnotetext{
${ }^{72}$ Ibidem, $\mathrm{fl}^{\circ} 177 \mathrm{v}$.

73 "Petição de Symão Estacio da Silveira, Madrid, 15 de junio de 1626", Revista do Instituto Histórico e Geographico Brasileiro, 1919: 96.
} 
aos Países Baixos que, com o tempo, começariam a atuar nesta mesma rota. Para o capitão, o novo caminho da prata passaria também a fornecer produtos maranhenses à carrera, os quais seriam melhores e mais baratos em relação aos do Peru. Para efetivar o negócio, Simão Estácio faz sete exigências ao rei. Vale a pena resumi-las:

1. Dinheiro suficiente para armar 500 homens durante um ano;

2. Fundação de uma nova cidade no rio Amazonas, com 500 moradores;

3. Dinheiro para levantar um Forte na entrada do rio Amazonas, com 200 soldados.

4. Garantia de que, cada ano, fossem enviados mais 200 moradores para povoar o dito núcleo urbano;

5. Que os moradores deveriam vir das Ilhas dos Açores;

6. Que estas despesas fossem integradas definitivamente ao Conselho da Fazenda.

7. Que o Monarca deveria passar provisão ao capitão Estácio da Silveira, concedendo-lhe todos os poderes sobre os moradores deste núcleo urbano, inclusive para aplicar «hasta la muerte civil y privación de los oficios». ${ }^{74}$

Este último item não é incomum neste tipo de proposição. Tal como demonstrou Guida Marques, a própria história da região não pode ser compreendida adequadamente sem levar em consideração as estratégias de promoção pessoal, e as rivalidades internas entre os grupos envolvidos. ${ }^{75}$ Os escritos de Simão Estácio da Silveira ganharam leitores e seguidores nas conquistas e no reino de Portugal. Um deles foi o futuro governador do Estado do Maranhão, Bento Maciel Parente. Numa relação, possivelmente escrita em 1630, Parente faz referência direta ao texto de Estácio da Silveira, corroborando sua proposta de «traer la plata de Tierra Firme, con brevedad, y con seguro, ahorrando los gastos, trabajos y peligros con que hoy se trae por Arica, por Mar del sur a Panamá, Puerto Belo, Cartagena y Habana». ${ }^{76}$

Uma interessante interpretação do caminho apresentado pelo capitão Simão Estácio da Silveira, em 1626, foi feita por Rosemarie Horch. Para Horch, o capitão talvez pretendesse passar os navios da carrera entre o complexo do rio Amazonas (pelo rio Solimões) e o rio Napo (18 léguas de Quito); passando

${ }^{74}$ Ibidem: 97-80.

${ }^{75}$ Marques, 2009: 319-337.

76 "Memorial, para conservar y augmentar la conquista y tierras del Marañon, y los indios que en ellas conquistó el Capitan Maior Bento Maciel Parente, son necesarias y convenientes las cosas siguientes", Revista do Instituto do Ceará, 1907: 186. 
depois a Porto Napo; seguindo o restante do caminho por terra até o Pacífico. Entretanto, há aqui um problema. Este trecho não poderia ser navegado com segurança no verão, por conta do aumento do nível dos rios durante o degelo andino. Com o degelo sazonal, as fortes correntezas impediriam o deslocamento dos barcos. Tudo isso, pressupondo que Simão Estácio da Silveira realmente conhecia as condições específicas do trajeto. ${ }^{77}$

Embora muitas das rotas pensadas para ligar o comércio das Índias espanholas ao Maranhão fossem pouco viáveis, os portugueses já tinham informações sobre o interesse de outros países nesta conexão. Em 1622, Filipe IV passa instruções diretas ao capitão Luís Aranha de Vasconcelos para tratar do descobrimento do rio Amazonas, confirmar a viabilidade das rotas e, também, combater a presença holandesa na região. O capitão Vasconcelos tinha à disposição: uma caravela, gente do mar, armas e mantimentos, e mais 100 mil reis de ajuda de custo. A jornada saiu do Grão-Pará em Junho de 1623, e contava com o auxílio de experientes navegadores portugueses: Pedro Teixeira, Antônio Vicente Cochado, e Bento Maciel Parente. ${ }^{78}$ Em 1624, o piloto-mor Antônio Vicente Cochado escreveu uma relação a respeito da jornada. Neste documento, a tópica da ameaça externa é onipresente. Segundo afirma o capitão Cochado, holandeses e ingleses já utilizavam a rota Maranhão-Índias, e por ela traficavam tabaco, algodão e pau-de-tinta. Os estrangeiros invernavam no Cabo do Norte, onde abasteciam seus navios com farinha, carne de porco, e pescado da terra, e de lá, segundo o capitão: «se vão às Índias, aonde fazem muito dano»». ${ }^{79}$ Portanto, a importância da jornada de 1623-24 está exatamente no seu caráter oficial, e no interesse da própria Monarquia em confirmar a viabilidade desta rota. ${ }^{80}$

Pouco tempo depois, o desastre da baía de Matanzas (1628), com a captura pelos holandeses de toda a frota das Índias, fez soar todos os alarmes. Sobre o tema, ainda em 1629, o Conselho de Estado recebe aviso do cardeal

77 Horch, 1985: 225-238.

78 Sobre o tema, ver: Lisboa, 12 de maio de 1625, AHU, Pará (avulsos), cx. 1, doc. 29. 3 de Julho de 1625, AHU, Pará (avulsos), cx. 1, doc. 30.

${ }^{79}$ Relação que faz Antonio Vicente Cochado do descobrimento do rio das Almazonas, e Cabo do Norte, que foi fazer por orden de V.Mag de, 27 de Julio de 1624, AGS, SP, 1467, fl ${ }^{\circ}$ 691v.

${ }^{80}$ Sobre o tema, ver: Cousas que pretende Luis Aranha de Vasconcelos $p^{a}{ }^{a}$ o descubrimento do Rio das Amazonas, e fortificação que ali se há de fazer, 18 de abril de 1625, AGS, SP, 1519, $\mathrm{fl}^{\circ}$. 28. REQUERIMENTO de Luís Aranha de Vasconcelos para o rei [D. Filipe III], solicitando ordens régias para seguir novamente para a região do rio Amazonas, com o objectivo de expulsar os invasores holandeses e ingleses que ali se encontram, ou concessão de licença para viajar até a cidade do Porto, sua terra nata, 3 de Julho de 1625, AHU, Pará (avulsos), cx. 1, doc. 30. 
de La Cueva sobre um novo plano holandês para a tomada das terras entre a costa do Estado do Brasil e o Peru. Segundo afirma o cardeal: «se tiene por cierto que procuraran tomar puestos fijos para proseguir sus intentos que son muy grandes a proporción de la ganancia que hicieron el año pasado». ${ }^{81}$ Não por acaso, propostas como as de Bento Maciel Parente, Luís Aranha de Vasconcelos e Simão Estácio da Silveira, desenvolvem a mesma estratégia discursiva, que resumindo seria: Espanha deveria aproveitar esta nova rota, antes que cheguem os holandeses.

\section{OUTROS INTERCÂMBIOS FLUVIAIS}

No contexto da América portuguesa, uma forte motivação para as propostas luso-maranhenses de estabelecimento de uma rota Maranhão-Peru-Sevilha são as informações sobre os intercâmbios reais existentes entre o Estado do Brasil e o rio da Prata. ${ }^{82}$ Não por acaso, existiam na época comparações sugestivas entre as duas bacias, o Prata, ao Sul, e o Amazonas, ao Norte. ${ }^{83}$ $\mathrm{Na}$ historiografia brasileira ainda faltam mais trabalhos comparativos entre as duas regiões. ${ }^{84} \mathrm{Em}$ ambos casos, há um reconhecimento por parte dos seus moradores de oportunidades econômicas na abertura de novas fronteiras a Oeste. Luso-americanos do Norte e do Sul alimentavam a mesma ambição: o acesso à prata castelhana e a adaptação de modelos hispano-peruanos de utilização do trabalho indígena. No caso específico de São Vicente (no Estado do Brasil), não deixa de existir expectativas maiores, alimentadas pelos mitos sobre a presença de metais preciosos no interior daquela capitania. ${ }^{85}$

Com relação à Amazônia Portuguesa, não se pode entender razoavelmente a sistematicidade das propostas de integração sem um olhar atento aos primeiros anos do governo de Filipe IV. Foi nesta época que as ideias sobre a integração Andes-Maranhão proliferaram, alimentadas pela ameaça holandesa e pelas promessas de investimento militar-comercial na época do duque de Olivares. ${ }^{86}$ Neste período, a própria realidade institucional da

${ }^{81}$ El Consejo de Estado a 10 de marzo de 1629 sobre lo que el Car. de La Cueva ha escrito en razon de las fuerzas maritimas que juntavan Olande=ses con intento de buscar los galeones de la plata/Madrid a 10 de marzo de 1629," AGS, Estado (Holanda), 2043, fl ${ }^{\circ} .159$.

${ }^{82}$ Sobre o tema, ver: Canabrava, 1984. Tejerina, 2004. Ruiz Gonsalez, 2002: 17-40; 2004.

${ }^{83}$ Gomes, 2001: 41-61.

${ }^{84}$ Uma tentativa foi feita por Martinière: Martinière, 1991a: 143-169.

${ }^{85}$ Ver, por exemplo: Consulta do Conselho de Portugal sobre as minas de San Vicente do Brasil, 26 de maio de 1607, AGS, SP, 1476, fl ${ }^{\circ}$ s. 156-159.

86 Serrano Mangas, 1989: 43. 
Monarquia Hispânica, entre os anos 1620-1640, resultou favorável a este tipo de propostas. Os seus proponentes, Simão Estácio da Silveira, Bento Maciel Parente, Luís Aranha de Vasconcelos, Manoel de Sousa de Eça, eram homens bem informados sobre os negócios da Monarquia, e apostavam forte na continuidade da situação de covassalagem entre hispano-peruanos e lusomaranhenses.

Por outro lado, sabe-se que os moradores da América portuguesa não estavam sozinhos na busca por enriquecimento nas Índias espanholas. De fato, tal como afirma James Boyajian, existe um amplo processo de transferência de interesses e expectativas não somente do Índico para o Atlântico, mas também de Lisboa para Sevilha e Cádis, envolvendo grupos inteiros de comerciantes portugueses que fugiam da desvalorização dos produtos asiáticos no mercado europeu, principalmente nos anos de 1620-40. Neste sentido, a crise da carreira da Índia representou a ascensão da carrera de Indias. Desta forma, entre muitos portugueses existia uma aposta na estabilidade da situação institucional gerada com a união dinástica que garantiria às comunidades de comerciantes a possibilidade de expansão dos negócios. ${ }^{87}$ É possível pensar também que a inclinação lusa pela América teria sido incentivada pelo aparente desinteresse que os Monarcas Habsburgo demonstravam sobre os temas asiáticos em comparação com os assuntos americanos. Contudo, paradoxalmente os súditos de Castela nunca descartaram completamente o Oriente como área de interesse, sobretudo depois de $1580 .{ }^{88}$ De qualquer forma, apesar das desconfianças, de parte a parte, para certos grupos de comerciantes a Restauração de Portugal (1640) foi algo tão prejudicial quanto indesejado. ${ }^{89}$

No início do século XVIII, com as notícias sobre a existência de minas de ouro no Mato Grosso, começa um novo ciclo de reconhecimento do potencial da fronteira hispano-lusa. Na mesma época, reinicia o velho sonho de encontrar um caminho fluvial economicamente viável entre as partes da América, agora na relação entre as vias fluviais amazônicas e o rio Guaporé, no centro do Estado do Brasil. ${ }^{90}$ Neste novo contexto, mais uma vez a fronteira não seria vista como termo, limite, mas como um espaço aberto a novos caminhos e possibilidades. Por fim, sabe-se que as tentativas de acesso ao comércio peruano, por parte de moradores da Amazônia, sobreviverão ao período da união dinástica, e podem ser documentadas até mesmo no século XIX. ${ }^{91}$

\footnotetext{
87 Boyajian, 2008: 202-219. Ver também: Pinto, 1998: 835-857.

88 Sobre o tema, ver: Valladares, 2001.

89 Valladares, 1993: 151-172; 2000: 23-36.

90 Araújo, 2010: 179-210. Teixeira, 1998: 78-92.

91 Bastos, 2010; 2008.
} 
Conclusão: um AtLÂNTICO LUSO-ESPANHOL?

A expectativa de participação na carrera das Índias demostra que a resposta portuguesa à união monárquica poderia ser tão variada quanto surpreendente. Não por acaso, nos últimos anos a reflexão acerca do papel da América portuguesa no contexto da Monarquia Hispânica tem superado claramente a tradicional interpretação nacionalista. Tais análises ajudaram a redefinir o ambiente político-jurídico que possibilitou a união de Coroas, a partir também de uma releitura crítica da contribuição de obras clássicas produzidas nos dois lados do Atlântico a exemplo de: Jaime Cortesão, ${ }^{92}$ Charles Boxer ${ }^{93}$ Alice Canabrava, ${ }^{94}$ Amaral Lapa,${ }^{95}$ Joaquim Veríssimo Serrão, ${ }^{96}$ Eduardo D’Oliveira França, ${ }^{97}$ Eulália Lobo, ${ }^{98}$ João Francisco Marques, ${ }^{99}$ Evaldo Cabral de Mello, ${ }^{100}$ entre outros. A compreensão dessa dinâmica também não negligenciou os temas econômicos, agora revisitados a partir de uma ótica menos relacionada à noção de dependência «metrópole-colônia». ${ }^{101}$ No Brasil, por exemplo, novas versões da história «colonial», em trabalhos coletivos ${ }^{102}$ ou nas monografias individuais, ${ }^{103}$ têm renovado o ambiente acadêmico ao propor comparações não só entre «colônias» e «metrópoles», mas também entre as próprias regiões ultramarinas. ${ }^{104}$

Assim, os atuais estudos sobre a Monarquia Hispânica têm enfatizado processos mais globais, transoceânicos e transfronteiriços, a partir da intersecção entre os diversos territórios e indivíduos que formavam a Monarquia Habsburgo. De modo geral, estes novos estudos vêm tentando avaliar o impacto global da Monarquia muito além do próprio território europeu. ${ }^{105}$ Para estes autores, o período em que Portugal integrou a Monarquia espanhola coincide com a

92 Cortesão, 1971.

93 Boxer, s.f.

${ }^{94}$ Canabrava, 1984.

${ }^{95}$ Lapa, 1968.

96 Serrão, 1956.

${ }^{97}$ França, 1997.

${ }_{98}$ Lobo, 1962.

99 Marques, 1989.

${ }^{100}$ Mello, 1975.

101 Novais, 1989.

102 Fragoso, Bicalho y Gouvea, 2001. Fragoso y Gouvea, 2009. Furtado, 2001. Lara y Mendonça, 2006.

${ }_{103}$ Bicalho, 2003. Fragoso, 1992. Lara, 2007. Souza, 2006.

104 Alencastro, 2000.

105 Valladares, 2001. Schaub, 2004. Cardim, 2004: 117-156. Marques, 2009. Ventura, 1997. Russell-Wood, 2002: 105-142. Molho y Curto, 2003: 569-579. Gruzinski, 2004. 
emergência de novas tendências do mercado-mundo, caracterizadas pela busca de novas conexões. Deste modo, passam a ser cada vez mais indispensáveis os estudos de caráter comparativo. ${ }^{106}$ Nesse sentido, talvez a melhor forma de entender a organização do «império» seja pensá-lo em termos de uma «Monarquia policêntrica», como sugerem Cardim, Ruiz Ibáñez e Sabatini, buscando compreender em que nível ocorria o reforço da identidade entre as partes. ${ }^{107}$

Assim, o estudo da Monarquia Hispânica não é mais um problema português e espanhol, e atrai cada vez mais a atenção de investigadores de outros centros universitários, como França, Inglaterra, Estados Unidos, Itália, além do Brasil. Nos últimos anos, a historiografia portuguesa também tem abordando de maneira dinâmica e inovadora o problema das mudanças institucionais e culturais referentes à Monarquia Hispânica, mas principalmente nos aspectos relativos à representação do poder. ${ }^{108}$

O estudo das novas rotas do Atlântico equatorial é parte do debate mais geral sobre a inserção da América na Monarquia Hispânica. ${ }^{109}$ Nesse sentido, talvez a mudança mais significativa ocorrida com a integração de Portugal a Castela seja a dinamização das redes de comunicação do Atlântico luso, fenômeno que alguns autores já chamaram de «atlantização». ${ }^{110}$ Como consequência, ao longo das últimas décadas do século XVI a circulação de prata, escravos, madeira, açúcar tornava as relações comerciais entre as duas partes cada vez mais simbiótica, favorecendo amiúde a livre associação entre homens de negócios portugueses e espanhóis. ${ }^{11}$

A integração de Portugal e dos portugueses de além-mar à Monarquia Hispânica, apesar do seu caráter político-dinástico, e muitas vezes militar, também pode ser considerada uma expressão tardia da enorme circulação mundial de pessoas, conhecimentos e mercadorias, ensejada pela dinamização dos circuitos oceânicos a partir do século XV, chamemos isso de «mundialização», «ocidentalização» ou até mesmo "globalização». ${ }^{112}$ Assim, estava claro que a união dinástica poderia criar com o tempo uma rede comercial interdependente entre Portugueses e Espanhóis. Além disso, muito antes do vínculo monárquico, Portugal e Espanha já compartilhavam interesses comuns

${ }^{106}$ Elliott, 2010. Gruzinski, 2001: 85-117. Subrahmanyan, 2007: 1359-1385.

107 Cardim, Ruiz Ibáñez y Sabatini, 2010: 15-34.

108 Entre outros, ver: Curto, 2011. Cardim, 2004: 117-156; 1998. Oliveira, 1990. Martínez Hernández, 2011: 69-96.

${ }^{109}$ Cardim, 2004: 117-156. Valladares, 1993: 151-172. Marques, 2009.

110 Este processo é definido, entre outros, por Godinho que enfatizou a superlatividade das rotas atlânticas após o final do século XVI. Godinho, 1990: 447-448.

111 Schwartz, 2008: 201-223. Alencastro, 2006: 339-385. Costa, 2006: 97-134.

112 Gruzinski, 2004. Putnam, 2006: 615-630. Ginzburg, 2005: 657-669. 
no mundo oceânico, participando de um mesmo movimento global. ${ }^{113}$ Aos olhos de muitos comerciantes portugueses as vantagens desta relação eram claras: o acesso à circulação de mercadorias do Vice-Reinado do Peru, ou ao fluxo da prata hispano-americana. ${ }^{114}$

De modo geral, portugueses e espanhóis são muito mais colaboradores que grandes rivais no complexo oceânico, associados de diversas maneiras para conter o avanço francês, inglês e holandês no Novo Mundo, antes mesmo da união dinástica. ${ }^{115}$ Evidentemente não se pode exagerar essas relações amistosas. Durante todo o período houve exemplos de rivalidade e conflitos por espaço de atuação, principalmente nas fronteiras. ${ }^{116}$ Entretanto, a Monarquia Hispânica foi frequentemente considerada uma oportunidade entre os contemporâneos, às vezes para obtenção de prestígio político, outras vezes de riqueza fácil, como foi o caso dos grandes e médios traficantes que atuavam nas rotas atlânticas. No período da união monárquica, como se sabe, os mercados do Rio de Janeiro e de Buenos Aires se relacionavam de maneira simbiótica, interdependentes de prata, escravos e grãos, com a participação ativa de ricos imigrantes portugueses na cidade castelhana. ${ }^{117}$ Tais relações impossibilitam levar a sério o mito oitocentista de um anticastelhanismo ortodoxo, ou como chamou Bouza Alvarez, o mito do «Antiunionismo iberista». ${ }^{118}$

No entanto, o tema da integração mais ativa entre os reinos que formavam a Monarquia Hispânica não era consenso na burocracia castelhana, nem mesmo na época do Conde-Duque. Amiúde existiam debates sobre a própria natureza da união dinástica, e sobre os prejuízos que esta acarretava algumas vezes a Castela. Para Geoffrey Parker, o próprio Filipe II, de Castela, não pensava numa integração total entre os reinos anexados. Por outro lado, como lembra I. A. A Thompson, apesar de tudo sempre existiu uma facção castelhana profundamente unionista que acreditava, como foi o caso de frei Juan de Salazar, autor da Política Española (1619), na necessidade de uma unidade político-religiosa efetiva contra os inimigos da comunidade católica ${ }^{119}$.

113 Subrahmanyan, 2007: 1359-1385. Molho, 2003: 569-579. Gruzinski, 2001: 85-117. Elliott, 2010.

${ }_{114}$ AGS, SP, 1476, $\mathrm{fl}^{\circ} \mathrm{s}$ 156-159.

115 Lucas Villanueva, 2001: 173-198.

116 Kuhn, 1999: 91-112.

117 Para um estudo completo sobre o tema, ver o clássico trabalho de Alice Canabrava: Canabrava, 1984. Para outras informações acerca da presença portuguesa em Buenos Aires, ver: Tejerina, 2004.

118 Bouza Alvarez, 1991: 223-249.

119 Thompson, 2002: 200-201. Sobre os conceitos de «pátria», «natio/nação» e as aspirações de formação de uma comunidade católica supranacional, ver: Gil Pujol, 2004: 39-76. 
Ao mesmo tempo, como afirma Anthony Pagden, a ideia de uma integração espiritual, mais que bélica e fiscal, estava presente entre grandes eruditos da época. ${ }^{120}$ Assim, se é verdade que os Monarcas Habsburgo não tinham uma política específica de integração, isto não significa que estes não tenham fornecido ferramentas aos vassalos para concebê-la.

No caso da conquista do Maranhão português, e das propostas de aproveitamento econômico de suas rotas naturais, uma das questões mais significativas, como já foi dito, havia sido o processo de adesão voluntária de diversos setores dessa sociedade, interessados no desenvolvimento de um mercado inter-regional a partir do contato entre as experiências «maranhense», «peruana» e «brasileira». Assim, parece claro, portanto, que não se pode pensar a Conquista do Maranhão fora dos quadros da Monarquia Hispânica. Nesse sentido, a pergunta primordial formulada por Parker, Allen, Pagden, entre outros, sobre a existência de uma estratégia global para a Monarquia espanhola ainda cobra sentido. ${ }^{121}$

\section{BiBLIOGRAFÍA}

Alencastro, Luiz Felipe de, $O$ trato dos viventes: formação do Brasil no Atlântico Sul, São Paulo, Companhia das Letras, 2000.

Alencastro, Luiz Felipe de, "Le versant brésilien de l'Atlantique-sud. 1550-1850", Annales. Histories, Sciences Sociales, 2 (París, março-abril 2006): 339-385.

Allen, Paul C., Felipe III y la Pax Hispanica, 1598-1621. El fracaso de la gran estrategia, Madrid, Alianza Editorial, 2001.

Araújo, Renata Malcher de, "Desenhar cidades no papel e no terreno: cartografia e urbanismo na Amazónia e Mato Grosso no século XVIII", Francisco Roque Oliveira e Héctor Mendoza Vargas (eds.), Mapas de metade do Mundo. Cartografia e a construção territorial dos espaços americanos. Séculos XVI a XIX, Lisboa/ Ciudad de México, Centro de Estudos Geográficos/Universidade de Lisboa/Instituto de Geografia/Universidad Nacional Autónoma de México, 2010: 179-210.

Ballabarba, Sergio, "Le navi portoghesi nel periodo delle scoperte", Piero Ceccucci (ed.), Le Caravelle Portoguesi sulle vie delle Indie, Roma, Bulzoni Editore/Consiglio Nazionale delle Ricerche/ CNCDP, 1993: 99-123.

Bastos, Carlos Augusto, "Comércio e fronteira entre Brasil e Peru: trocas mercantis e conflitos locais", III Conferência Internacional em História Econômica/ V Encontro de Pós-Graduação em História Econômica, Brasília, 2010.

120 Pagden, 1991: 94.

121 Parker, 1998. Allen, 2001. Pagden, 1997. 
Bastos, Carlos Augusto, "Nas Rotas do Grão-Pará e Loreto: comércio e fugas nas Amazônias peruana e brasileira (1840-c.1870)", Anais do VIII Encontro Internacional da ANPHLAC, Vitória, 2008.

Bastos, Carlos Augusto e Lopes, Siméia de Nazaré, "Nas rotas do Xingu e do Tapajós: desertores, remeiros e regatões no Grão-Pará do pós-Cabanagem”, Alírio Cardozo e César Martins de Souza (eds.), Histórias do Xingu: Fronteiras, espaços e territorialidades: séculos XVII-XXI, Belém, Edufpa, 2008: 159-188.

Berredo, Bernardo Pereira de, Anais Históricos do Estado do Maranhão, São Luis, Alumar, 1988 [1749].

Bethencourt, Francisco, "Configurações políticas e poderes locais", Francisco Bethencourt e Diogo Ramada Curto (eds.), A Expansão Marítima Portuguesa, 1400-1800, Lisboa, Edições 70, 2010: 207-264.

Bicalho, Maria Fernanda, A Cidade e o Império: O Rio de Janeiro no século XVII, Rio de Janeiro, Civilização Brasileira, 2003.

Bluteau, Pe. Raphael, Vocabulario portuguez e latino. Coimbra, Collegio das Artes da Companhia de Jesus, 1712, ed. fac-simile, CD-Rom, Rio de Janeiro, UERJ, s.d.

Bouza Alvarez, Fernando Jesús, "Gramática de la Crisis. Una nota sobre la historiografía del 1640 hispánico entre 1940 y 1990”, Cuadernos de Historia Moderna, 11 (Madrid, 1991): 223-249.

Boxer, Charles, O Império Marítimo Português (1415-1825), Lisboa, Edições 70, s.f.

Boyajian, James C., Portuguese Trade in Asia under the Habsburgs, 1580-1640, Baltimore/Londres, The Johns hopkins University Press, 2008.

Câmara, Antônio Alves, Ensaio sobre as construcções navaes indígenas do Brasil, Rio de Janeiro, Typ. De G. Leuzinger \& filhos, 1888.

Canabrava, Alice Piffer, O comércio português no Rio da Prata (1580-1640), São Paulo, Editora Itatiaia/Editora da Universidade de São Paulo, 1984.

Cardim, Pedro, "O governo e a administração do Brasil sob os Habsburgo e os primeiros Bragança”, Hispania, LXIV/216 (Madrid, janeiro-abril 2004): 117-156.

Cardim, Pedro, Cortes e cultura política no Portugal do Antigo Regime, Lisboa, Edições Cosmos, 1998.

Cardim, Pedro; Ruiz Ibáñez, José Javier e Sabatini, Gaetano, “Introduzione”, Gaetano Sabatini (ed.), Comprendere le Monarchie Iberiche. Risorse Materiali e rappresentazioni del potere, Roma, Viella, 2010: 15-34.

Cardoso, Alírio y Chambouleyron, Rafael, "Fronteiras da Cristandade: Relatos jesuíticos no Maranhão e Grão-Pará (século XVII)", Mary Del Priore e Flávio Gomes, Senhores dos Rios. Amazônia, Margens e História, Rio de Janeiro, Elsevier, 2003: 33-62. 
Cardoso, Alírio, "Maranhão na Monarquia Hispânica: intercâmbios, guerra e navegação nas fronteiras das Índias de Castela (1580-1655)", Salamanca, Universidad de Salamanca [Tese de doutorado inédita], 2012.

Cardozo, Alírio, “Cerca de Castilla, lejos de Brasil. La construcción política de la Amazonía brasileña (Maranhão) bajo la Unión Ibérica (1600-1621)”, Gabriela Dalla Corte, Pilar Garcia Jordán, Javier Laviña, Natàlia Moragas, Ricard Piqueras, José Luis Ruiz-Peinado y Tous, Meritxell, (eds.), Sociedades diversas, sociedades en cambio. América Latina en perspectiva histórica, Barcelona, Universitat de Barcelona, 2011: 165-176.

Cardozo, Alírio, “Um atalho para a fortuna”, Revista de História, 26, ano 3 (Rio de Janeiro, 2007): 60-63.

Carreira, António, Os portugueses nos rios da Guiné (1500-1900), Lisboa, 1984.

Chambouleyron, Rafael, "A Amazônia Colonial e as Ilhas Atlânticas", Canoa do Tempo, 2/1 (Manaus, 2008): 187-204.

Chambouleyron, Rafael, "Portuguese Colonization of Amazon Region, 1640-1706", Universidade de Cambridge (Tese de doutorado inédita), 2005.

Cipolla, Carlo, Conquistadores, Piratas e Mercadores. A saga da prata espanhola, Lisboa, Editorial Teorema, 2002.

Coates, Timothy J., Degredados e órfãos: colonização dirigida pela coroa no império português. 1550-1755, Lisboa, CNCDP, 1998.

Corrêa, Helidacy Maria Muniz, "Para aumento da conquista e bom governo dos moradores. O papel da câmara de São Luís na conquista, defesa e organização do território do Maranhão (1615-1668)", Universidade Federal Fluminense (Tese de doutorado inédita), 2011.

Cortesão, Jaime, O Ultramar Português depois da Restauração, Lisboa, Portugália Editora, 1971.

Costa, Leonor Freire, "Entre o açúcar e o ouro: permanência e mudança na organização dos fluxos (séculos XVII e XVIII)", João Fragoso, Manolo Florentino, Antônio Carlos Jucá, e Adriana Campos (eds.), Nas rotas do Império. Eixos mercantis, tráfico e relações sociais no mundo português, Vitória/Lisboa, Edufes/ IICT, 2006: 97-134.

Costa, Leonor Freire, Naus e galeões na Ribeira de Lisboa. A construção naval no século XVI para a Rota do Cabo, Caiscais, Patrimónia, 1997.

Costa, Leonor Freire, O transporte no Atlântico e a Companhia Geral do Comércio do Brasil (1580-1663), Lisboa, CNCDP, vol. 1, 2002.

Curto, Diogo Ramada, Cultura Política no tempo dos Filipes (1580-1640), Lisboa, edições 70, 2011. 
D’abbeville, Claude, História da missão dos padres capuchinhos na ilha do Maranhão, Belo Horizonte/São Paulo, Itatiaia/Edusp, 1975 [1614].

Delson, Roberta Marx, "Inland navigation in Colonial Brazil: using Canoes on the Amazon", International Journal of Maritime History, 7/1 (Terra Nova e Labrador, jun. 1995): 1-28.

Domingues, Francisco Contente, Os Navios do Mar Oceano. Teoria e empiria na arquitectura naval portuguesa dos séculos XVI e XVII, Lisboa, Fundação para a Ciência e a Tecnologia/Centro de História da Universidade de Lisboa, 2004.

Elliott, John H., España, Europa y el Mundo de Ultramar (1500-1800), Madrid, Taurus, 2010.

Fragoso, João e Gouvea, Maria de Fátima (eds.), Na Trama das Redes: política e negócio no Império português. Séculos XVI-XVIII, Rio de Janeiro, Civilização Brasileira, 2009.

Fragoso, João, Homens de Grossa Aventura: acumulação e hierarquia na praça comercial do Rio de Janeiro (1790-1830), Rio de Janeiro, Arquivo Nacional, 1992.

Fragoso, João; Bicalho, Maria Fernanda e Gouvea, Maria de Fátima (eds.), O Antigo Regime nos Trópicos: A Dinâmica Imperial Portuguesa (séc.s XVI-XVIII), Rio de Janeiro, Civilização Brasileira, 2001.

França, Eduardo D’Oliveira, Portugal na época da Restauração, São Paulo, Hucitec, 1997.

Furtado, Júnia (ed.), Diálogos Oceânicos. Minas Gerais e as novas abordagens para uma História do Império Ultramarino Português, Belo Horizonte, UFMG, 2001.

Gil Pujol, Xavier, "Un rey, una fe, muchas naciones. Patria y nación en la España de los siglos XVI y XVII", Antonio Álvarez-Ossorio Alvariño y Bernardo J. García García, (eds.), La Monarquía de las Naciones. Patria, nación y naturaleza en la Monarquía de España, Madrid, Fundación Carlos de Amberes, 2004: 39-76.

Ginzburg, Carlo, "Memoria e Globalizzazione”, Quaderni Storici, 120/XL/fasc. 3 (Bologna, Dezembro 2005): 657-669.

Godinho, Vitorino Magalhães, Mito e mercadoria, utopia e prática de navegar (séculos XIII-XVIII), Lisboa, DIFEL, 1990: 447-448.

Gomes, Plínio Freire, “O Amazonas e o Prata na mitogeografia da América”, Topoi (Rio de Janeiro, set. 2001): 41-61.

Gruzinski, Serge, "Le mondes mêles de la Monarchie Catholique et autres 'connected histories"”, Annales. Histories, Sciences Sociales, 1 (París, janeiro-fevereiro 2001): 85-117.

Gruzinski, Serge, Les quatres parties du monde: histoire d'une mondialization, Paris, Éditions de Martinière, 2004. 
Hansen, Adolfo João, A sátira e o engenho: Gregório de Matos e Bahia do século XVII, São Paulo/Campinas, Ateliê editorial/Editora da Unicamp, 2004.

Hespanha, António Manuel, “A constituição do Império português. Revisão de alguns enviesamentos corrente", João Fragoso, Maria de Fátima Gouvea e Maria Fernanda Bicalho (orgs.), O Antigo Regime nos Trópicos: a dinâmica imperial portuguesa (séculos XVI-XVIII), Rio de Janeiro, Civilização Brasileira, 2001: 163-188.

Holanda, Sérgio Buarque de, Monções, São Paulo, Brasiliense, 2000.

Horch, Rosemarie Erika, "Tentativas de penetração amazônica por vias fluviais no século XVII", Separata da Revista da Universidade de Coimbra, XXXII (Coimbra, 1985): 225-238.

Hutter, Lucy Maffei, "A madeira do Brasil na construção e reparos de embarcações", Separata da Revista da Universidade de Coimbra, XXXIII (Coimbra, 1985): 418419.

Kantor, Iris, "Usos Diplomáticos da Ilha Brasil. Polêmicas cartográficas e historiográficas", Vária História, 23/37 (Belo Horizonte, janeiro-junho 2007): 70-80.

Kiemen, Mathias C., The indian policy of Portugal in the Amazon region,1614-1693, Washington, The Catholic University of America, 1954.

Kuhn, Fábio, "A fronteira em movimento: relações luso-castelhanas na segunda metade do século XVIII", Estudos Ibero-Americanos, Revista da PUCRS, 25 (Porto Alegre, 1999): 91-112

Lapa, José Roberto do Amaral, A Bahia e a Carreira da Índia, São Paulo, Companhia Editora Nacional/Editora da Universidade de São Paulo, 1968.

Lara, Silvia Hunold e Mendonça, Joseli Maria N. (eds.), Direitos e Justiças no Brasil, Campinas, Editora da Unicamp, 2006.

Lara, Silvia Hunold, Fragmentos setecentistas: escravidão, cultura e poder na América Portuguesa, São Paulo, Companhia das Letras, 2007.

Leite, Serafim, S. J., Luiz Figueira, sua vida heróica e sua obra literária, Lisboa, Agência Geral das Colônias, 1940.

Lobo, Eulália Maria Lahmeyer, Processo Administrativo Ibero-Americano (Aspecto Sócio-Econômicos - Período Colonial), Rio de Janeiro, Biblioteca do Exército, 1962.

Lucas Villanueva, Oscar, "Las relaciones financieras entre España y Portugal, 15631580”, Studia Historica, 23 (Salamanca, 2001): 173-198.

Marques, Guida, "L'Invention du Bresil entre deux monarchies. Gouvernement et pratiques politiques de l'Amérique portugaise dans l'union iberique (1580-1640)", Paris, Ecole des Hautes Etudes en Sciences Sociales (Tese de doutorado inédita), 2009. 
Marques, João Francisco, A Parenética Portuguesa e a Restauração, 1640-1668. A revolta e a mentalidade, Porto, Instituto Nacional de Investigação Científica/Universidade do Porto, 1989.

Martínez Hernández, Santiago (eds.), Governo, Política e Representações do Poder no Portugal Habsburgo e nos seus Territórios Ultramarinos (1581-1640), Lisboa, CHAM/Universidade Nova de Lisboa/Universidade dos Açores, 2011: 69-96.

Martinière, Guy, "Geopolítica do espaço português da América. O 'Estado do Brasil' e o domínio paulista: do planalto Central à expansão meridional”, Frédéric Mauro (ed.), O Império Luso-Brasileiro (1620-1750), Lisboa, Estampa, vol. VII, 1991a: 143-169.

Martinière, Guy, "Geopolítica do espaço português da América: o Estado do Maranhão", Frédéric Mauro (ed.), O Império Luso-Brasileiro (1620-1750), vol. VII, Lisboa, Estampa, $1991 b$.

Mauro, Frédéric, A expansão Europeia, Lisboa, Estampa, 1995.

Mauro, Frédéric, Portugal, o Brasil e o Atlântico, 1570-1670, vol.1, Lisboa, Editorial Estampa, 1997.

Mello, Evaldo Cabral de, Olinda restaurada: guerra e açúcar no nordeste, 1630-1654, Rio de Janeiro/São Paulo, Forense Universitária/edusp, 1975.

Mena García, Carmen, "Nuevos datos sobre bastimentos y envases en armada y flotas de la Carrera", Revista de Indias, LXIV/231 (Madrid, maio-agosto 2004): 447-484.

Molho, Anthony e Curto, Diogo Ramada, "Les réseaux Marchands à l'époque moderne”, Annales. Histories, Sciences Sociales, 3 (París, Maio-Junho 2003): 569-579;

Novais, Fernando, Portugal e Brasil na crise do Antigo Sistema Colonial (1777-1808), São Paulo, Hucitec, 1989.

Oliveira, António de, Poder e Posição Política em Portugal no período Filipino (15801640), Lisboa, DIFEL, 1990.

Pagden, Anthony, El imperialismo español y la imaginación política. Estudios sobre teoría social y politica europea e hispanoamericana (1513-1830), Barcelona, Planeta, 1991.

Pagden, Anthony, Señores de todo el mundo. Ideologías del imperio en España, Inglaterra y Francia (en los siglos XVI, XVII y XVIII), Barcelona, Ediciones Península, 1997.

Parker, Geoffrey, La gran estrategia de Felipe II, Madrid, Alianza Editorial, 1998.

Parker, Geoffrey, La revolución militar. La innovación militar y apogeo de Occidente, 1500-1800, Madrid, Alianza Editorial, 2002.

Pinto, Celsa, "Twilight of Carreira da Índia", Artur Teodoro de Matos e Luís Filipe F. Reis Thomaz, A Carreira da Índia e a rota dos estreitos, Actas do VIII Seminário Internacional de História Indo-Portuguesa, Braga, 1998: 835-857. 
Putnam, Lara, "To study the fragments/whole: microhistory and Atlantic world", The Journal of Modern History, 39/3 (Chicago, 2006): 615-630.

Reid, Anthony, Southeast Asia in the Age of Commerce, 1450-1680, Volume One: The lands below the winds, New Haven/London, Yale University Press, 1988.

Rodrigues, José Damião, São Miguel no século XVIII. Casa, elites e poder, Ponta Delgada, Instituto Cultural de Ponta Delgada, 2003.

Rodrigues, José Damião e Madeira, Artur Boavida, "Rivalidades imperiais e emigração: os açorianos no Maranhão e no Pará nos séculos XVII e XVIII", Anais de História de Além-Mar, I (Lisboa, 2003): 247-263.

Rodrigues, José Honório, História da História do Brasil. $1^{a}$ parte: historiografia colonial, São Paulo, Companhia Editora Nacional, 1979.

Ruiz Gonsalez, Rafael, "La política legislativa con relación a los indígenas en la región sur de Brasil durante la unión de las coronas (1580-1640)", Revista de Indias, LXII/224 (Madrid, janeiro-abril 2002): 17-40.

Ruiz Gonsalez, Rafael, São Paulo na Monarquia Hispánica, São Paulo, Instituto Brasileiro de Filosofia e Ciência Raimundo Lulio, 2004.

Russell-Wood, A. J. R.. "Padrões de Colonização no Império Português, 1400-1800”, Francisco Bethencourt y Diogo Ramada Curto (eds.), A Expansão Marítima Portuguesa, 1400-1800, Lisboa, Edições 70, 2010: 171-206.

Russel-Wood, A. J. R, Um Mundo em Movimento. Os Portugueses na África, Ásia e América (1415-1808), Lisboa, DIFEL, 1992.

Russel-Wood, A. J. R., "Centers and Peripheries in the Luso-Brazilian World, 15001808'. Christine Daniels e Michael V Kennedy, Negotiated Impires: centre and peripheries in the Americas, 1500-1820, Nova York, Routledge, 2002: 105-142.

Salgado, Augusto António Alves, "Portugal e o Atlântico. Organização militar e acções navais durante o período filipino (1580-1640)", Lisboa, Universidade de Lisboa [Tese de doutorado inédita], 2009.

Santos Pérez, José Manuel, "Colonial fortifications in the State of Maranhão: historical Research in Spain and Portugal”, Atlas of Dutch Brazil, Amsterdam, New Holland Foundation, 2009.

Santos, José Manuel e Petit, Pere, La Amazônia em perspectiva histórica, Salamanca, ediciones Universidad de Salamanca, 2006.

Santos, José Manuel e Cabral, George, El desafio holandés al domínio Ibérico en Brasil en el siglo XVII, Salamanca, ediciones Universidad de Salamanca, 2006.

Schaub, Jean-Frédéric, La Francia española. Las raíces hispanas del absolutismo francés, Madrid, Marcial Pons, 2004.

Schwartz, Stuart B, "Prata, açúcar e escravos: de como o império resgatou Portugal". Tempo, 12/24 (Río de Janeiro, 2008): 201-223. 
Serrano Mangas, Fernando, Armada y flotas de la plata (1620-1648), Madrid, Banco de España, 1989.

Serrão, Joaquim Veríssimo, O reinado de D. António Prior do Crato (1580-1582). Vol. 1., Coimbra, 1956.

Silveira, Simão Estácio da, "Relação Sumaria das Cousas do Maranhão. Escripta pello capitão Symao Estácio da Sylveira, Dirigida aos pobres deste Reyno de Portugal [1624]", Separata dos Anais da Biblioteca Nacional, 94 (1974), Rio de Janeiro, Biblioteca Nacional, 1976.

Souza, Laura de Mello e, O Sol e a Sombra. Política e administração na América portuguesa do século XVIII, São Paulo, Companhia das Letras, 2006.

Studart, Barão de, "Documentos para a história do Brasil, especialmente para a do Ceará", Fortaleza, 1 (1904): 43-45.

Studart, Barão de, Documentos para a história do Brasil, especialmente para a do Ceará, Revista Trimensal do Instituto do Ceará, Fortaleza, Typographia Studart, 1910-1924.

Subrahmanyam, Sanjay, Comércio e conflito. A presença Portuguesa no Golfo de Bengala, 1500-1700, Lisboa, Edições 70, 1994.

Subrahmanyan, Sanjay, "Holding the world in balance: the connected histories of the Iberian Overseas Empires, 1500-1640", American Historical Review, 112/5 (Indiana, dezembro 2007): 1359-1385.

Tavares Bastos, Aureliano Cândido, O Valle do Amazonas. Estudo sobre a livre navegação do Amazonas. Estatistica, producções, commércio, questões fiscaes, do valle do Amazonas, Rio de Janeiro, B.L Garnier, 1866.

Teixeira, Marco António Domingues, “O comércio e as rotas fluviais na sociedade guaporena colonial”, Revista de Educação, Cultura e Meio Ambiente, 3/II (Porto Belho, 1998): 78-92.

Tejerina, Marcela, Luso-brasileños en el Buenos Aires Virreinal. Trabajo, negocios e intereses en la plaza naviera y comercial, Bahía Blanca, Editorial de la Universidad Nacional del Sur, 2004.

Unger, Richard W., Ships and Shipping in the North Sea and Atlantic, 1400-1800, Aldershot/Brookfield, Ashgate, 1997.

Valladares, Rafael, "Brasil: De la unión de coronas a la crisis de Sacramento (15801680)", José Manuel Santos Pérez (eds.), Acuarela de Brasil. 500 años después. Seis ensayos sobre la realidad histórica y económica brasileña, Salamanca, Aquilafuente/Ediciones Universidad de Salamanca, 2000: 23-36.

Valladares, Rafael, "El Brasil y las Indias españolas durante la sublevación de Portugal (1640-1668)", Cuadernos de Historia Moderna, 4 (Madrid, 1993): 151-172. 
Valladares, Rafael, Castilla y Portugal en Ásia (1580-1680), declive imperial y adaptación, Louvain, Leuven University Press, 2001.

Ventura, Graça M., A união ibérica e o mundo atlântico, Lisboa, Colibri, 1997.

Wätjen, Hermann, O Domínio Colonial Holandês no Brasil. Um capítulo da história colonial do século XVII, Recife, Governo de Pernambuco/Companhia Editora de Pernambuco, 2004.

Fecha de recepción: 22 de febrero de 2013.

Fecha de aceptación: 8 de julio de 2013.

\section{AMAZONIA Y LA CARRERA DE INDIAS: navegación hacia el norte de la América portuguesa en la época de la Monarquía Hispánica}

El antiguo Estado de Maranhão y Grão Pará, hoy equivalente a los actuales estados de la Amazonia brasileña, no pertenecía a las rutas de navegación hacia el Estado de Brasil. Durante la primera mitad del siglo XVII los portugueses que habitaban esa región se plantearon participar en la Carrera de Indias aprovechando la facilidad de navegación hacia el Virreinato del Perú y el Caribe. Este artículo tiene como objetivo analizar la reacción de los portugueses de las zonas de frontera respecto a la integración de Portugal en la Monarquía Hispánica (1580-1640). Para este trabajo, utilizamos fuentes sobre las diversas propuestas de participación portuguesa en la ruta de navegación hispano-peruana encontradas hoy en diferentes archivos portugueses, brasileños y españoles.

Palabras Clave: Amazonia; Estado de Maranhão; Monarquía Hispánica; navegación; siglo XVII. 


\section{AMAZON AND THE INDIES RUN: navigation to the north of Portuguese America during the Hispanic Monarchy}

The old State of Maranhão and Pará Grão, now equivalent to the current states of the Brazilian Amazon, did not belong to the shipping lanes to the State of Brazil. Throughout the first half of the seventeenth century the Portuguese who inhabited that region raised participate in the Carrera de Indias leveraging the ease of navigation to the Viceroyalty of Peru and the Caribbean. This article aims to analyze the reaction of the Portuguese border areas for the integration of Portugal in the Spanish Monarchy (1580-1640). For this work, we use sources on the various proposals of Portuguese participation in the breadcrumb Spanish-Peruvian different files found today in Portugal, Brazil and Spain.

KEY WORDS: Amazon; Maranhão; Hispanic Monarchy; navigation; seventeenth century. 